Buca Eğitim Fakültesi Dergisi, 2021, say1 51, s. 210-225

Derleme Makalesi
The Journal of Buca Faculty of

Education, 2021, issue 51, p. 210-225

Review Article

\title{
İlkokulda Matematiksel Modelleme İçin Bir Öğretim Süreci
}

\section{A Teaching Process for Mathematical Modeling in Primary School}

\author{
H. Beyza CANBAZOĞLU $U^{1}$, Kamuran TARIM ${ }^{2}$
}

${ }^{1}$ Sorumlu Yazar, Arş. Gör., Temel Eğitim Bölümü, Eğitim Fakültesi, Çukurova Üniversitesi,
Türkiye, beyza.cnbzgl0@gmail.com, (https://orcid.org/0000-0001-5596-5019)
${ }^{2}$ Prof.Dr., Matematikve Fen Bilimleri Eğitimi Bölümü, Eğitim Fakültesi, Çukurova Üniversitesi,
Türkiye, kamuran.tarim@gmail.com, (https://orcid.org/0000-0002-2048- 5207)

Geliş Tarihi: 13/11/2020

Kabul Tarihi: 10/04/2021

\section{ÖZ}

İlkokul matematik dersi öğretim programı, çevresinde ve okul ortamı içerisinde öğrendiklerini anlamlandırabilen ve kendine ait anlamlar oluşturabilen, oluşturduğu anlamları günlük yaşam içerisinde karşılaştığ 1 durumlara uygulayabilen bireyler yetiştirmeyi hedeflemektedir. Bu bağlamda matematik eğitimi, matematik ve günlük yaşam arasında anlamlı ilişkilerin kurulduğu uygulamalara yönelmiştir. Matematik öğretiminde matematik ve günlük yaşam ilişkisinin önem kazanmasıyla birlikte matematiksel model ve modelleme süreçleri, öğretme ve öğretme süreçlerinde karşımıza çıkmaktadır. Bu nedenle "İlkokulda matematiksel modelleme nasıl inşa edilmeli ve uygulanmalı?" sorusunun yanıtlanması gerekliliği ortaya çıkmaktadır. Bu gereklilik göz önüne alındığında matematiksel modelleme etkinliklerinin ilkokulda yaygınlaştırılması ve sınıf öğretmenlerine öğrenme-öğretme sürecinde kullanabilecekleri bir öğretim sürecinin ve örnek etkinlik uygulamalarının sağlanmasının önemli olduğu düşünülmektedir. Bu bağlamda araştırma kapsamında ilkokulda matematiksel modellemenin uygulanabilmesi için Carlson, Wickstrom, Burroughs ve Fulton (2016) tarafindan ortaya konulan öğretim süreci açıklanmış ve bu süreç doğrultusunda bir modelleme etkinliği örneğine yer verilmiştir.

Anahtar Kelimeler: Matematiksel modelleme, model oluşturma etkinlikleri, ilkokul, matematik öğretimi.

\begin{abstract}
It aims to raise individuals who can make sense of what they have learned and create their own meanings around the primary school mathematics curriculum and in the school environment, and apply their meanings to the situations they encounter in daily life. In this context, mathematics education has been directed to the applications where meaningful relationships are established between mathematics and daily life. With the importance of mathematics and daily life in mathematics teaching, mathematical model and modeling processes appear in teaching and teaching processes. Therefore, "How should mathematical modeling be built and applied in primary school period?" the question arises that it must be answered. Considering this requirement, it is considered important to expand mathematical modeling activities in primary school and to provide a teaching framework and exemplary activities that they can use in the teaching process of primary school teachers. In this context, in order to apply mathematical modeling during the primary school years, the teaching framework put forward by Carlson, Wickstrom, Burroughs and Fulton (2016) has been explained and an example of modeling activity has been included in this framework.
\end{abstract}

Keywords: Mathematical modeling, model eliciting activity, primary school, teaching mathematics. 


\section{GİRIŞ̧}

İlkokul matematik dersi öğretim programı, çevresinde ve okul ortamı içerisinde öğrendiklerini anlamlandırabilen ve kendine ait anlamlar oluşturabilen, oluşturduğu anlamları günlük yaşam içerisinde karşılaştığı durumlara uygulayabilen bireyler yetiştirmeyi hedeflemektedir (Milli Eğitim Bakanlığı [MEB], 2018). Bu bağlamda matematik eğitimi, matematik ve günlük yaşam arasında anlamlı ilişkilerin kurulduğu uygulamalara yönelmiştir (De Corte, 2004). Matematik öğretiminde matematik ve günlük yaşam ilişkisinin önem kazanmasıyla birlikte matematiksel model ve modelleme süreçleri, öğretme ve öğretme süreçlerinde ortaya çıkmaktadır (Lesh, Hamilton ve Kaput, 2007). İlkokul yıllarından itibaren matematiksel modelleme süreçlerini içeren model oluşturma etkinliklerinin kullanılması, programda bahsedilen öğrenme-öğretme süreçlerinin oluşturulmasında faydalı olacak süreçlerdir (Carlson, Wickstrom, Burroughs ve Fulton, 2016; English, 2006; Şahin ve Eraslan, 2018).

English, Fox ve Watters (2005) modelleri bir durumu inşa etmek, yorumlamak, açıklamak ve matematiksel olarak tanımlamak için kullanılan kavramsal sistemler olarak ifade etmektedir. Alternatif olarak, Lesh ve Fennewald (2010) modelin, belirli bir amaç için başka bir sistemi tanımlamak (veya açıklamak veya tasarlamak) için bir sistem olduğunu açıklamaktadır. Bu doğrultuda matematiksel model, bir gerçek yaşam durumun yorumlanmasına, çözümlenmesine olanak sağlayan zihindeki yapıların matematiksel bir forma dönüştürülmüş dış temsilleridir (Lesh ve Doerr, 2003). Günlük yaşamda karşılaşılan problem durumlarını matematiksel yollarla çözebilmek için fonksiyon, eşitsizlik, değişken ve formül gibi matematiksel modeller kullanılmaktadır (Lesh ve Doerr, 2003; Lingefjärd, 2006). Matematiksel modelleme ise gerçek dünya fenomenlerini temsil etmek, analiz etmek, tahminlerde bulunmak ya da başka bir şekilde içgörü sağlamak için matematiğin kullanıldığı bir süreçtir (Bliss ve Libertini, 2016). Matematiksel modelleme sürecinde, matematiksel modeller kurularak, gerçek yaşam çözümüne ulaşılmaya çalışılmaktadır (Bukova Güzel, Tekin Dede, Hıdıroğlu, Kula Ünver ve Özaltun Çelik, 2018, s. 11). Bu bağlamda matematiksel modelleme, otantik senaryoları matematik dünyasına çevrildiğinde başlayan döngüsel bir süreçtir. Bu süreçte bireyler, çözümler bulmak için uygun araçları ve yöntemleri seçmekte ve kullanmakta, sonra doğrulamak için çözümleri gerçek dünyaya yeniden uygulamaktadırlar. Gerekirse, gelişmiş çözümler üretmek için modeller geliştirmektedirler. $\mathrm{Bu}$ doğrultuda matematiksel modelleme, bu sürecin tamamındaki ilişki olarak karşımıza çıkmaktadır.

Lesh ve Doerr'e (2003) göre matematiksel modelleme, model oluşturma etkinliklerinin bir basamağ1 veya model oluşturma etkinlikleri sürecinde gerçekleşen bir süreç olarak ifade edilmektedir. Bu doğrultuda model oluşturma etkinlikleri; öğrencilerin gruplar hâlinde işbirliği içinde çalş̧arak genellenebilir ve prototip olabilecek bir model oluşturabilmeleri için pek çok olasılığa dayalı çözümler üretmeleri istenen, olası farklı çözümler içeren, rutin olmayan, gerçek hayatla ilişkilendirilmiş problem türleridir (Lesh ve Doerr, 2003). Model oluşturma etkinlikleri, günlük hayatında matematiği kullanabilen, matematik ve gerçek yaşam durumları arasında ilişki kurabilen, karşılaştığı problem durumlarına çeşitli çözüm yolları üretebilen, günlük yaşamda karşılaştı̆̆ problem durumlarının üstesinden gelebilen, analitik ve yaratıcı düşünebilen bireylerin yetiştirilmesinde bireylere zengin ve çeşitli fırsatlar sunmaktadır (Blum ve Niss, 1991; English ve Watters, 2005; Lesh ve Doerr, 2003).

Öğrencilerin, matematiği günlük yaşam ile ilişkilendirme becerilerini bir başka deyişle matematik okuryazarlığı becerilerini ölçmeyi hedefleyen PISA uygulamaları, matematiksel model ve modelleme süreçlerini önemle vurgulamaktadır. $\mathrm{Bu}$ doğrultuda PISA değerlendirmesinde ülkelere göre başarı sıralamasına bakıldığında, Türkiye'nin matematik ve matematik okuryazarlığı performansının katılımcı ülkelerin çoğunun altında kaldığı ve başarı siralamasında alt siralarda yer aldığı görülmektedir (Organisation for Economic Co-operation and Development [OECD], 2019a, 2019b). Bu sebeple öğrencileri ilkokul yıllarından itibaren 
gerçek yaşam problem durumlarını içeren matematiksel modelleme etkinlikleri ile karşı karşıya getirmenin önemi ortaya çıkmaktadır (Carlson ve diğerleri, 2016; English, 2012; Verschaffel ve De Corte, 1997; Watters, English ve Mahoney, 2004).

Matematiksel becerilere sahip olmak, öğrencileri matematik okuryazarı birey hâline getirmeyebilir (Carlson ve diğerleri, 2016). İlkokul matematik dersi öğretim programında (MEB, 2018) öğrencilerin matematik okuryazarlığını geliştirmeye yönelik amaç ve kazanımlar yer almasına rağmen çoğu matematik veya sınıf öğretmeni nadiren matematik derslerini, öğrencilerin günlük yaşamıyla ilişkilendirmeyi denemektedir (Steen, Turner ve Burkhardt, 2007). Bu nedenle öğrenciler, matematik ve günlük yaşam arasında bağlantı kuramamakta (Tran ve Dougherty, 2014) ve öğrendikleri bilgileri karşılaştıkları problem durumlarına uygulama fırsatını kaçırmaktadırlar (Verschaffel, De Corte ve Vierstraete, 1999). Bu bağlamda matematiksel modelleme öğrencilerin, matematiğin dünyaya katılımını ve anlayışını nasıl desteklediğini görmelerine yardımcı olarak matematik okuryazarlığını geliştirmektedir (Carlson ve diğerleri, 2016).

Yapılan çalışmalar geleneksel öğrenme-öğretme yaklaşımlarının, bireylerin ihtiyaç duydukları problem çözme, ilişkilendirme, akıl yürütme ve iletişim kurma gibi temel matematiksel becerilerini geliştiremeyeceğini vurgulamaktadır (English ve Watters, 2004; Greer, 1997; Mousoulides, Christou ve Sriraman, 2006; National Council of Teachers Mathematics [NCTM], 2000; Zawojevski, Lesh ve English, 2003). Almanya, Amerika, Avustralya, Finlandiya, İsviçre, İsveç, Singapur gibi matematikte başarılı olan daha birçok ülkede ilkokuldan yükseköğretime kadar her kademede uygulanmakta olan matematik dersi öğretim programlarında, matematiksel modellemenin önemli bir yere sahip olduğu belirtilmektedir (Blomhøj ve Kjeldsen, 2006; Lingefjärd, 2006; Maaß, 2006; NCTM, 2000; Skolverket, 1997; Stillman, Galbraith, Brown ve Edwards, 2007; Swedish Ministry of Education, 1994). Öğrencilerin günlük yaşam ve matematik ilişkisini kurduğu, derin ve anlamlı bir matematik anlayışı geliştirmeleri önemlidir. O zaman "Neden öğrencilere matematiksel modellemeyi öğretmek için liseye kadar beklemeliyiz?" (Carlson ve diğerleri, 2016). Öğrenciler bir ortamda öğrenilen bilgileri, otomatik olarak diğerine aktaramazlar (Darling-Hammond ve Austin, 2014). Eğitim yılları, doğru cevaplara ulaşmak için egzersizler yaparak geçiren öğrencinin, aniden matematiği, dünyayı anlamlandırmasına yardımcı olacak bir araç olarak görmesini beklemenin bir anlamı yoktur (Carlson ve diğerleri, 2016). Bu nedenle matematiksel modelleme eğitimi ilkokuldan itibaren başlamalıdır (Carlson ve diğerleri, 2016; Verschaffel ve De Corte, 1997; Watters, English ve Mahoney, 2004).

İlkokul matematik dersi öğretim programında, matematiksel modelleme becerisine ilk defa 2015 y1lında yer verilmiştir (MEB, 2015). Matematiksel modelleme, ilkokul matematik dersi öğretim programında altı temel beceriden biri olarak yer almaktadır. Ancak 2018 ilkokul matematik dersi öğretim programı incelendiğinde, kazanımların matematiksel modelleme yerine matematiği modellemeye yönelik olduğu dikkati çekmektedir (MEB, 2018).

İlkokul çocukları ile matematiksel modellemeye yönelik çalışmaların, uluslararası literatürde önemli bir yer tuttuğu görülmektedir (An ve Oh, 2018; Carlson ve diğerleri, 2016; English, 2003a, 2006, 2007, 2010; English ve Watters, 2004, 2005; Ko ve Oh, 2015; Mousoulides, Christou ve Sriraman, 2008; Panaoura, 2012; Suh, Matson ve Seshaiyer, 2017; Watters, English ve Mahoney, 2004; Wickstrom, 2017; Xin, Lin, Zhang ve Yan, 2007). Bu çalışmalara örnek olarak; Suh, Matson ve Seshaiyer (2017), model oluşturma etkinliklerinin ilkokul üçüncü sınıf öğrencilerinin hangi 21. yy becerilerini ortaya çıkardığını ve süreç içerisinde sınıf öğretmeninin pedagojik uygulamalarını ortaya koymayı hedeflemiştir. Bu doğrultuda matematiksel modelleme sürecinde öğrencilerin, eleştirel düşünme ve problem çözme, yaratıcılık ve yenilikçilik, işbirliği ve iletişim 21. yy becerileri sergiledikleri belirlenmiştir. Öğretmenlerin ise süreç içerisinde öğrenmeye odaklama, öğretilebilir anlar yakalama, program bilgisine sahip olma ve öğrenciler tarafindan üretilen eserleri kullanma gibi pedagojik uygulamaları sergiledikleri belirlenmiştir. Bir başka çalışmada ise Wickstrom (2017), 
sınıfa matematiksel modelleme etkinliği getirildiğinde sınıf içerisinde neler olduğunu belirlemeyi amaçlamıştır. Bu doğrultuda matematiksel modellemenin, gerçek dünya bağlamında matematiği bilme ve yapmanın ne anlama geldiğine ilişkin bir araç olabileceği sonucuna ulaşılmıştır. English ve Watters $(2004,2005)$ tarafından yapılan çalışmada ise model oluşturma etkinlikleri ile ilkokul üçüncü sınıf öğrencilerinin ( 8 yaş) matematiksel modelleme becerileri incelenmiştir. Model oluşturma etkinlikleri, öğrencilerin üst-biliş ve eleştirel düşünme becerilerini geliştirdiği, farklı temsillerle düşüncelerin ifade edilmesi için zengin ortamlar oluşturduğu sonucuna ulaşılmıştır.

Ulusal literatürde matematiksel modellemeye yönelik çalışmaların genellikle ortaokul, lise düzeyi ve matematik öğretmeni veya matematik öğretmeni adaylarıyla yapılan çalışmaların yoğunlukta olduğu görülmektedir (Akyol ve Şendurur, 2019; Çavuş Erdem ve Gürbüz, 2018; Deniz ve Akgün, 2016; Doğan, Gürbüz, Çavuş Erdem ve Şahin, 2018; Hıdıroğlu ve Bukova Güzel, 2016; Hıdıroğlu ve Özkan Hıdıroğlu, 2017; Işı1k ve Mercan, 2015; İnan Tutkun ve Didiş Kabar, 2018; Özaltun Çelik ve Bukova Güzel, 2018; Özer ve Bukova Güzel, 2016; Şahin, Doğan, Gürbüz ve Çavuş Erdem, 2017; Tekin Dede ve Yılmaz; Tural Sönmez, 2019). Ancak ulusal literatürde ilkokul düzeyinde öğrencilerin model oluşturma süreçlerini incelenmesine yönelik sınırlı çalışmaya ulaşılmışıır (Şahin, 2014, 2019; Şahin ve Eraslan, 2016, 2017, 2018; Ulu, 2017). Şahin ve Eraslan (2016) tarafindan yapılan çalışmada, ilkokul dördüncü sınıf öğrencilerinin matematiksel modelleme etkinliği ile modelleme süreçleri belirlenmeye çalışılmıştır. Şahin ve Eraslan (2017) tarafından yapılan bir başka çalışmada ise yine matematiksel modelleme etkinliğinde ilkokul dördüncü sınıf öğrencilerinin modelleme süreçleri belirlenmeye çalışılmıştır. Benzer şekilde Ulu (2017) tarafindan yapılan çalışmada da ilkokul dördüncü sınıf öğrencilerinin alışveriş problemine yönelik modelleme süreçleri ortaya koyulmuştur. İlkokul düzeyine yönelik sınırlı sayıda yapılan çalışmalar incelendiğinde, araştırmaların odak noktasının modelleme süreçleri olduğu ortaya çıkmaktadır. Ancak ilkokulda matematiksel modellemenin süreç içerisinde kullanımına yönelik ne tür uygulamaların yapılması gerektiği ve bunun örnek uygulamalarına yönelik çalışma bulunmamaktadır. Şahin ve Eraslan (2018) tarafından yapılan çalışmada, "Ilkokulda model oluşturma etkinlikleri nasıl uygulanmalı?" sorusuna yanıt aranmıştır. Ancak bu çalışmada model oluşturma etkinliklerine, her öğretim düzeyini kapsayacak genel çerçevede yer verilmiştir. Bu nedenle "İlkokulda matematiksel modelleme nasıl inşa edilmeli ve uygulanmalı?" sorusunun yanıtlanması gerekliliği karşımıza çıkmaktadır. Bu eksiklik göz önüne alındığında matematiksel modelleme etkinliklerinin ilkokulda yaygınlaştırılması ve sınıf öğretmenlerine öğrenme-öğretme sürecinde kullanabilecekleri bir öğretim sürecinin ve örnek etkinlik uygulamalarının sağlanmasının önemli olduğu düşünülmektedir. $\mathrm{Bu}$ bağlamda araştırmanın amacı ilkokulda matematiksel modellemenin uygulanabilmesi için Carlson, Wickstrom, Burroughs ve Fulton (2016) tarafından ortaya konulan öğretim sürecini sunmak ve bu süreç doğrultusunda bir modelleme etkinliği örneğine yer vermektir.

\section{İLKOKULDA MATEMATIKSEL MODELLEME İÇİN ÖĞRETIM SÜRECI}

Carlson ve diğerleri (2016), ilkokul sınıflarında matematiksel modelleme için bir öğretim süreci ortaya koymuşlardır. Bu öğretim süreci gerçek yaşam problem durumunu sunma ve ön hazırlık (developing and anticipating), uygulama (enacting) ve tekrar gözden geçirme (revisiting) basamaklarından oluşmaktadır (Bkz. Şekil 1). 


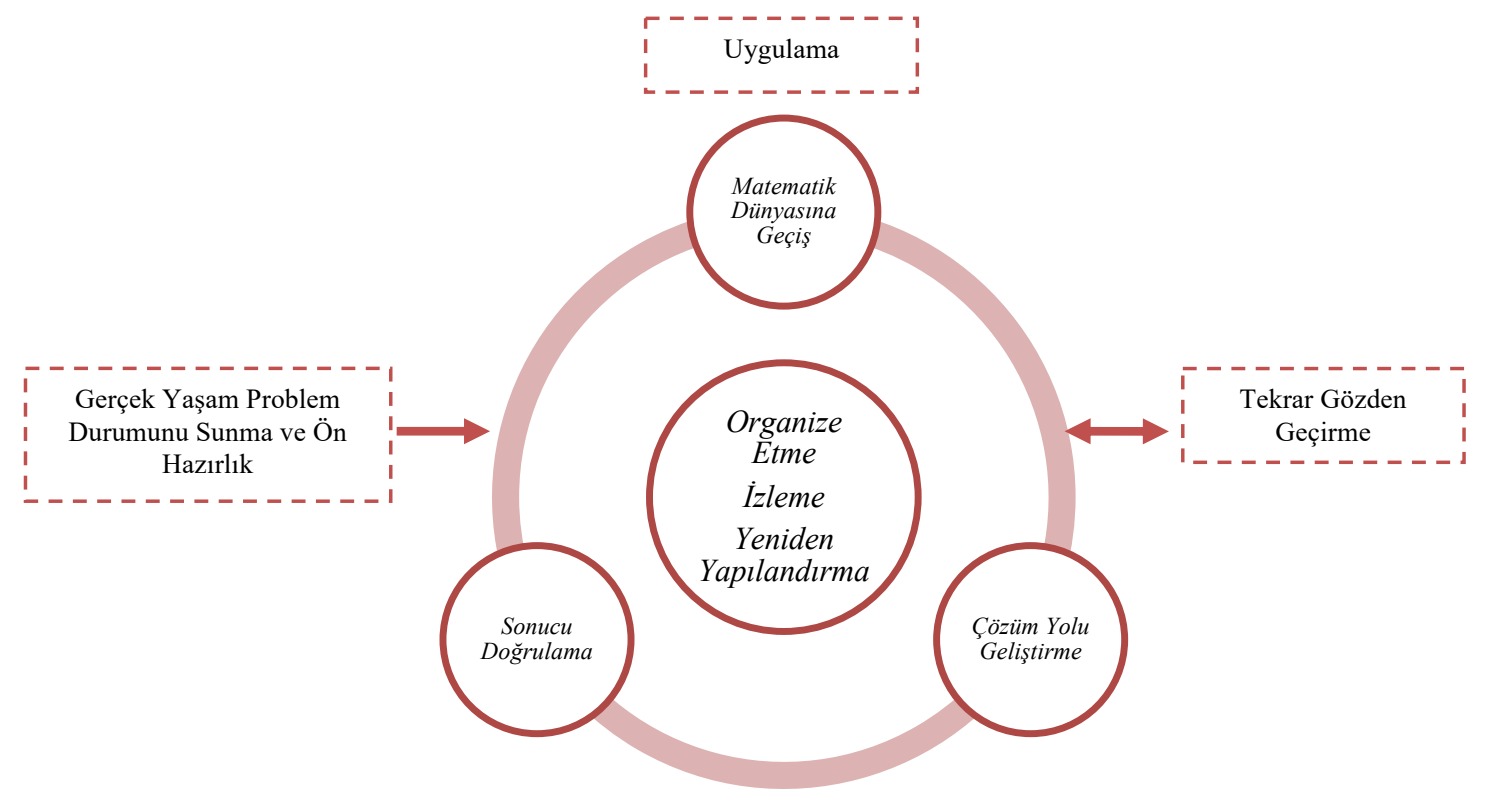

Şekil 1. Modelleme Döngüsü Yapısı (Carlson ve diğerleri, 2016)

\subsection{Gerçek Yaşam Problem Durumunu Sunma ve Ön Hazırlık (Developing and Anticipating)}

Gerçek yaşam problem durumunu sunma aşamasında, öğretmen modelleme görevini hazırlamaktadır. Bir başka deyişle öğretmen öğrencilere, model oluşturma etkinliğini sunmaktadır. Gerçek yaşam problem durumu, öğrencilere sunulan matematiksel içeriği ve süreç araçlarını, değerlendirmeyi ve ilgi alanlarını belirlemeyi içermektedir. Model oluşturma sürecinde öğrenciler, sorunları çözmek için kendi deneyimlerini ve bilgilerini kullanmaktadırlar. Model oluşturma etkinlikleri, öğrenciler için erişilebilir olanlardan türetilmelidir. Başka bir deyişle öğrencinin günlük yaşamında yer alan, anlamlandırabileceği ve deneyim sağlayabileceği model oluşturma etkinlikleri kullanılmalıdır.

Ön hazırlık, gelişmekte olan evrenin ikincil bir yüzüdür. Modelleme, belirsiz bir süreçtir. $\mathrm{Bu}$ nedenle öğretmenin öğrenci sorularını, stratejilerini ve olası kavram yanılgılarını önceden tahmin etmesi ve nasıl cevap vereceğini düşünmesi önemlidir. Gerçek yaşam problem durumunu sunma ve ön hazırlık basamağında, sınıf öğretmenleri için yol gösterici sorular şu şekildedir:

1. Öğrencilere sunulan model oluşturma etkinliği, tüm öğrenciler için ilgi çekici ve anlamlı midir?

2. Öğrenciler modelleme sürecine girerken neler yapabilir?

3. Öğrenciler modelleme sürecine girerken hangi matematiksel kavramları veya işlemleri kullanabilir?

4. Öğrenciler model oluşturma etkinliğinde, hangi noktaları anlamakta zorlanabilir?

5. Öğrencilerin problem durumunu anlamalarını sağlayabilmem için öğrencilere nasıl sorular sormaliyım?

\subsection{Uygulama (Enacting)}

Bağlam, bir başka deyişle model oluşturma etkinliği belirlendiğinde, sınıf modelleme döngüsüne geçer. Uygulama, öğrencilerin matematiksel modelleme sürecine katıldığı ve öğretmenin bireysel olarak öğrencilerin ve tüm sınıfın ilerlemesini ve anlamasını sağladığı, desteklediği ve ilerlettiği ortak bir çalışmadır. Bu süreçte öğretmen organize etme, izleme ve yeniden yapılandırma süreçlerini gerçekleştirir. Bir anlamda öğretmen artık rehber konumundadır. Öğrenciler ise matematik dünyasına geçiş, çözüm yolu geliştirme ve sonucu doğrulama süreçlerini gerçekleştirir. 


\section{a. Organize Etme, İzleme ve Yeniden Yapılandırma Döngüsü (The Organize, Monitor, Regroup Cycle)}

Modelleme sürecinde, bireysel çalışma eğiliminde olan öğrenciler ile karşılaşılabilmektedir. Bu süreçte sınıf öğretmenleri, tüm sınıfın birlikte çalışmasını dengelemek durumundadır. Bir başka deyişle öğretmen, öğrencileri birlikte çalışmaya yönlendirmelidir. $\mathrm{Bu}$ doğrultuda sınıf öğretmeni, öğrencileri modelleme sürecine dâhil olmaları için düzenler, ögrencilerin çalışmalarını izler ve gelişmekte olan fikirleri paylaşmaları için sınıfı yeniden yapılandırır. Yeniden yapılandırma süreci, ortaya çıkan fikirler doğrultusunda oluşan yeni bakış açılarıdır. Sadece öğrencilerin dikkatini yeni oluşan fikirlere çekmek için yapılan bir eylemdir. Bir başka deyişle oluşan grupları dağıtma eylemi değil, ortaya çıkan yeni fikirlere dikkat çekme eylemidir. "Bu açıdan bakabilir miyiz?", "Sizce bu nasıl bir fikir?" gibi sorularla öğrencileri yeni fikirlere yönlendirerek yeniden yapılandırma döngüsü gerçekleştirilmiş olur. $\mathrm{Bu}$ süreç, modelleme sürecinde birkaç kez meydana gelebilir.

\section{b. Matematik Dünyasına Geçiş (Posing Questions)}

Model oluşturma sürecinde öğrenciler, verilen durumla ilgili matematiksel sorular sormay1 ve kurmayı öğrenirler. Bu süreçte öğrenciler, problem durumunda yer alan verilenleri ve istenenleri belirlemektedirler. Bir başka deyişle gerçek dünyadaki problemleri matematik dünyasına çevirme sürecinde, öğrenciler sabit olduğu varsayılan bağlamsal faktörlerle (sınırlılıklar) ve değişecek olan bağlamsal faktörlerle (değişkenler) çalışır. Öğrenciler, sınırlılıkları ve değişkenleri belirleyerek problemin çözümüne yönelik varsayımlar oluşturmaya başlarlar. Öğrencilerin gerçek yaşam problem durumunu matematik dünyasına çevirme çalışmalarını desteklemeleri için öğretmenlerin aşağıdaki soruları düşünmeleri önerilir:

1. Problem durumunda verilenler ve istenenler ne/lerdir?

2. Problem durumunda yer alan sınırlılıklar ve değişkenler ne/lerdir?

3. Öğrenciler sınırlılıkları ve değişkenleri belirleyemezse, öğrencilere nasıl sorular sormaliyım?

\section{c. Çözüm Yolu Gelişstirme (Building Solutions)}

Öğrenciler matematiksel problemi tanımladıktan, sınırlılıkları ve değişkenleri tartıştıktan sonra, çözümler geliştirirler. Bu noktada öğretmenler ve öğrenciler, bir süreç olarak modellemeye odaklanmalı ve bir sonuç olarak "model"e odaklanmamalıdırlar. Bu aşamada öğrenciden beklenen, matematiksel model elde etmesi ve elde edilen modeli çözüme ulaştırmasıdır. Sınıf öğretmeninin, öğrencilerin bir çözüme yönelik çalıştıkları sırada aşağıdaki soruları sık sık kendilerine sormaları önerilir:

1. Öğrencilerin oluşturabileceği matematiksel model/ler neler olabilir?

2. Model oluşturma sürecinde öğrencilere soracağım sorular nasıl olmalı?

3. Doğru modeli oluşturabilmeleri için öğrencilere nasıl sorular sormalıyım?

4. Bu süreçte öğrenciler hangi matematiksel kavramları veya işlemleri keşfedebilir?

5. Kavramların veya işlemlerin keşfedilmesi sırasında, öğrencilerde nasıl farkındalıklar oluşturabilirim?

\section{d. Sonucu Doğrulama (Validating Conclusions)}

Sonucu doğrulama sürecinde öğrenciler, problemi anlama ile verilenleri ve istenenleri belirleme süreçlerini, çözüm varsayımlarını, oluşturdukları matematiksel modeli, matematiksel modelin çözümünü ve elde ettikleri matematiksel sonucun gerçek yaşamdaki problem durumunu karşılayıp karşılamadığını kontrol ederler. Doğrulama, çözümü, ilk sorunun ortaya çıktığı duruma geri çevirmeyi ve hangi varsayımların geçerli olduğunu görmek için test etmeyi içerir. Öğrencilerin modelleri değerlendirme ve test etmeyi öğrenmesi, sürecin kritik bir parçasıdır. Bu basamak, kendi başına bir öğrenme sonucu olarak düşünülmelidir. Öğrencileri çözümlerini değerlendirirken desteklemek için, sınıf öğretmeninin sorularını, öğrencilerin çalışmalarına ve 
varsayımlarına göre uyarlaması gerekmektedir. Aşağıdaki soruların öğretmenlere, modelleme döngüsü boyunca yansıma yapmalarına yardımcı olacağı düşünülmektedir:

1. Öğrenciler hangi çözüm varsayımlarını yapıyorlar?

2. Öğrenci çalışmalarının güçlü ve zayıf yönleri nelerdir?

3. Öğrencilere, farklı bakış açılarını kullanarak modellerini geliştirmeleri için hangi soruları sorabilirim?

\subsection{Tekrar Gözden Geçirme (Revisiting)}

Modelleme görevlerini yerine getirirken yaratılan bilgi, sınıfın göreve yeni bir mercekle tekrar bakması için firsatlar sunar. $\mathrm{Bu}$ süreçte öğrenciler, modellemede yeni bağlamlarda değiştirilebilecek ve kullanılabilecek yeni araçlar ve stratejiler icat edebilirler. Aynı şekilde, öğrenciler eğitim-öğretim sürecinde henüz öğrenmedikleri matematiksel kavramları veya araçları keşfedebilir, kullanabilir ve yeni bakış açıları geliştirebilirler. Sınıf öğretmenlerine, modelleme görevinin tekrar gözden geçirme fırsatlarını değerlendirirken yol gösterecek sorular şu şekildedir:

1. Süreç içerisinde keşfedilen matematiksel kavramlara yönelik farkındalık kazandırmak için neler yapabilirim?

2. Öğrencilerin model oluşturma etkinliğine yeni bir bakış açısı ile bakmalarını sağlayabilmek için nasıl sorular sormalıyım?

3. Model oluşturma etkinliğindeki hangi bağlamlar veya değişkenler, göreve yeni bir bakış açısıyla bakmayı mümkün kılabilir?

4. Öğrencilerin süreç içerisinde ortaya çıkan matematik bilgileri, oluşturulan matematiksel modelde değişimlere yol açabilir mi?

\section{ILKOKULDA MODEL OLUŞTURMA ETKINLIIĞİ VE UYGULAMA SÜRECİ}

Okulda Kermes Problemi, Carlson ve diğerlerinin (2016) çalışmasından Türkçeye uyarlanmıştır. Uyarlama sürecinde problemin ilkokul öğrencilerinin (4. sınıf), yaş seviyesine uygun ve anlaşı1ır olmasına dikkat edilmiştir. Okulda kermes problemi, okulda gerçekleşecek bir yardım (nasıl bir yardım türü olduğuna sınıf öğretmeni karar verebilir) için bir model oluşturma etkinliğidir. Bu doğrultuda "Bir kermes için en iyi yiyecek nedir?" problemi ile öğrenciler modelleme sürecine katılmaya başlamaktadırlar.

Okulda kermes probleminde öğrencilerden veri toplamaları, değişkenleri ve sınırlılıkları belirlemeleri, yorumlamaları, analiz ederek birleştirmeleri, nitel olarak verilen veriyi nicel veriler ile ilişkilendirmeleri ve kâr modeli oluşturmaları istenmektedir. Ayrıca bu problem Doerr ve English'in (2003) de önerdiği gibi öğrencilerin grup çalışması yapabilmelerine, problem durumundaki verileri çeşitli temsil biçimlerinde sunmalarına, genellenebilir ve prototip bir model oluşturmalarına, ulaştıkları çözümleri yazılı ve sözlü olarak paylaşmalarına firsat tanıyan bir model oluşturma etkinliğidir.

\subsection{Geliştirme ve Tahmin Etme Basamağı}

Sınıf öğretmeni, okulunda gerçekleşecek kermes için bir modelleme görevi tasarlamaktadır. Sınıf öğretmeni öğrencilerinin, üç basamaklı sayıları çarpabildiğini ve bölebildiğini, çok basamaklı aritmetik işlemleri yapabildiğini ve tablo, grafik oluşturabildiğini kabul etmektedir. Bu süreçte öğrenciler, sorunları çözmek ve akıl yürütmelerini başkalarına iletmek için birlikte çalışabilmektedirler.

Sınıf öğretmeni, aşağıdaki problem durumunu öğrencilere sunar:

\section{"Bir kermes için en iyi yiyecek nedir?"}

Sınıf öğretmeni, öğrencilerin modelleme sürecine girerken yapabilecekleri seçimleri dikkate almaktadır. Bu süreçte öğretmen öğrencilerin "en iyi” bağlamını, farklı şekillerde 
tanımlayacağını tahmin etmelidir. Örneğin; en iyi tat, en düşük maliyet, en sevilen yiyecek gibi faktörleri göz önünde bulundurarak öğrenciler modelleme sürecine girebilirler. $\mathrm{Bu}$ durumda öğretmenin öğrencilerin fikirlerini, problemde verilen iki ana öğeye çekmesi gerekmektedir. $\mathrm{Bu}$ iki ana öğe: en iyi yiyecek ve kâr elde etme (kermes olduğu için).

\subsection{Uygulama}

Burada öğretmen, öğrencilerin matematik dünyasına geçiş, çözüm üretme ve sonucu doğrulama süreçlerini gerçekleştirmesine rehberlik eder. Bir başka deyişle öğretmen, öğrencilerin bu adımları başarabilmeleri için organize etme, izleme ve yeniden yapılandırma süreçlerini gerçekleştirir.

\section{a. Matematik Dünyasına Geçiş}

Öğrenciler okulda kermes problem durumunu matematik dünyasına çevirirken, "en iyi" kelimesinin öznel olduğunu keşfederler. Bu süreçte öğrenciler en iyi yiyeceği, "en lezzetli", "herkes için iyi yiyecek" ve "çok para kazandıran yiyecek" olarak tanımlayabilirler. Öğretmen bu süreçte öğrencilerin model oluşturmalarını sağlayabilmek için şu soruları sorabilir:

1. Kermeslerde hangi yiyecek en çok tercih ediliyordur?

2. Seçeceğimiz hangi yiyecek en kârlı olabilir?

Sınıf öğretmeni, öğrencilerinden en çok tercih edilen yiyecekle ilgili değişkenleri düşünmelerini ister. Sonra sınıftan belirledikleri değișkenlerin, yiyecekle ilgili kararlarını nasıl etkileyebileceğini tartışmalarını ister. Modelleme döngüsünün ilerleyen süreçlerinde öğrencilerin, kâr ile ilgili faktörleri göz önünde bulundurmaları beklenmektedir. Aynı zamanda sınıfin değişkenleri ve sınırlılıkları belirlemesi gerekmektedir. Örneğin bazı faktörlerin sabit olduğu (örneğin, kermesin okulun spor salonunda tutulması zorunluluğu gibi), bazılarının ise değişken (örneğin, yiyecek fiyatı gibi) olduğu sonucuna varmaları beklenmektedir. Öğrenciler bu süreçte tablolar oluşturabilir ve yorumlayabilirler.

\section{b. Çözüm Yolu Geliştirme}

Öğrenciler, bu süreçte insanların kermeslerde en çok tercih ettikleri yiyecek/leri araştırırlar. Bunun sonucunda bir veya birden fazla seçenek belirleyebilirler. Yiyeceği belirledikten sonra öğrencilerin kermesde satacakları yiyeceği, ne kadara satmaları gerektiğine karar vermeleri gerekmektedir. $\mathrm{Bu}$ kararı verirken bir yardım için bu etkinliği düzenlemeleri sebebiyle, öğrencilerden yiyecekten kâr etmeleri gerektiğini göz önünde bulundurmaları beklenmektedir. Ayrıca öğrencilerin kârı hesaplayabilmeleri için yiyeceğin maliyetini tahmin etmeleri gerekmektedir. Bu süreçte ortaya çıkabilecek varsayımlar şunlar olabilir:

- Diyelim ki öğrenciler kermes için seçtikleri yiyeceğin maliyetinin 15 TL olduğunu buldular. Bunun için öğrenciler kâr edebilmek için seçtikleri yiyeceği 16 TL'ye satabileceklerine karar verdiler.

- Öğrenciler, aldıkları yiyeceklerin tümünü satabileceklerini varsayabilirler. Bu doğrultuda öğrenciler tarafından oluşturulabilecek matematiksel model şu şekildedir:

$$
\text { kâr }=0,5 x \text { kişi sayısı }
$$

Sınıf öğretmeni bu noktada, oluşturulan matematiksel modelin güçlü yönlerini ve sınırlılıklarını tartışmaya açabilir ve ögrencilerine şu soruyu yöneltebilir (Varsayalım $k i$ ögrenciler 100 kişilik yiyecek aldılar.):

\section{"100 kişiye yiyecek alırsanı ancak sadece 64 kişi gelirse ne olur?"}

$\mathrm{Bu}$ süreçte öğrencilerin oluşturdukları matematiksel modeli tekrar gözden geçirmeleri beklenmektedir. Ve öğrencilerin ulaşması gereken kâr modeli şu şekilde olmalıdır:

\section{kâr $=($ kişi başı maliyet $x$ satılan yiyecek sayısı) - toplam yiyecek maliyeti}


- Bir başka varsayım olarak, öğrenciler seçtikleri yiyeceğin maliyetinin 15 TL olduğunu buldular ve kâr edebilmek için seçtikleri yiyeceği 15,5 TL'ye satabileceklerine karar verdiler.

- $\mathrm{Bu}$ süreçte yiyecek başına kârı hesaplayabilmek için 0,50 ile kişi sayısını çarpmaya çalışan gruplar da olabilir. O zaman sınıf öğretmeni, 0,50 ile $\frac{1}{2}$ arasında ilişki kurmak için bu firsatı kullanabilir. Böylece öğrenciler problemlerini çözmek için yarım kavramını düşünebilirler.

c. Sописи Doğrulama

$\mathrm{Bu}$ süreçte öğrenciler, elde ettikleri matematiksel çözümlerin gerçek yaşamdaki problem durumunun çözümü için uygun olup olmadığını kontrol etmektedir. Öğrenciler bu aşamada kendilerine bazı sorular sorarak matematiksel süreçlerini tekrar gözden geçireceklerdir:

1. Problemi doğru anlayabildim mi?

2. Verilenleri ve istenenleri doğru belirleyebildim mi?

3. Çözüm için değişkenleri doğru belirleyebildim mi?

4. Bu değişkenleri kullanarak doğru matematiksel model/ler oluşturabildim mi?

5. Problemi gerçek yaşam bağlamında doğru yorumlayabildim mi?

$\mathrm{Bu}$ doğrultuda sınıf öğretmeni de öğrencilerinin anlamlı bir şekilde doğrulama sürecini gerçekleştirebilmeleri için şu soruları sorabilir:

1. Problem sizden ne/ler istiyordu?

2. Problemi çözebilmek için hangi değişken/lere ihtiyacımız vardı?

3. Bu değişken/leri doğru belirlediğinizi düşünüyor musunuz? Neden?

4. Bulduğunuz matematiksel sonucun, sizi asıl problemin sonucuna götürdüğünü düşünüyor musunuz? Neden?

5. Bulduğunuz matematiksel sonucu gerçek yaşam bağlamında nasıl yorumlayabilirsiniz?

\subsection{Tekrar Gözden Geçirme}

$\mathrm{Bu}$ aşamaya kadar öğrenciler, en iyi yiyecek ve kâr elde etme üzerinde çalışmış oldular. Sınıf öğretmeni, gerçek yaşam problem durumuna tekrardan bakmaları için sınıfa şu soruyu sorabilir:

\section{“En iyi” kelimesini bu problem için başka nasıl düşünebiliriz?}

Öğrencilerin "en iyi”" kelimesini yeniden anlamlandırmaları sağlanmalıdır. Örneğin Hayat Bilgisi dersi ile ilişkilendirerek "en iyi" kelimesini, sağlık açısından yeniden değerlendirmeleri sağlanabilir. Yeniden tanımladıkları "en iyi" yemeği tekrar araştırmaları ve oluşturdukları kâr modeline uygulamaları istenebilir. Böylece oluşturdukları modelin genellenebilir olduğunu fark etmeleri sağlanır.

\section{SONUÇ}

Matematiksel modellemenin ve model oluşturma etkinliklerinin ilkokulda yaygınlaştırılması ve sınıf öğretmenlerine öğrenme-öğretme sürecinde kullanabilecekleri bir öğretim sürecinin ve örnek etkinlik uygulamalarının sağlanmasının önemli olduğu düşünülmektedir. Carlson ve diğerleri (2016) ilkokul düzeyi için model oluşturma etkinliklerinin sınırlı olduğunu bundan dolayı ilkokul öğrencileri için model oluşturma etkinliklerinin geliştirilmesine ihtiyaç duyulduğunu ifade etmektedirler. Bu çalışma ile ilkokulda matematiksel modellemenin uygulanabilmesi için Carlson ve diğerleri (2016) tarafindan ortaya konan bir öğretim süreci sunulmuş ve bu süreç doğrultusunda ilkokul öğrencileri için bir modelleme etkinliği örneğine yer verilmiştir. Bu öğretim süreci incelendiğinde, son yıllarda matematiksel modellemeyi bağlamsal temelli bir yaklaşımla ele alan model ve modelleme perspektifi teorik yaklaşımı üzerine temellendirildiği kanısını oluşturmaktadır. $\mathrm{Bu}$ teorik 
yaklaşıma göre model oluşturma etkinlikleri, öğrencilerin gerçek yaşamdaki bir durumu yorumlamalarını ve kendilerinin anlamlandırabildikleri şekilde matematikselleştirmelerini sağlamaktadır (Lesh ve Doerr, 2003). Bu yaklaşımdaki temel amaç, matematiksel kavramların ve işlemlerin gerçek yaşam ile ilişkisinden yararlanılarak, öğrencilerin daha etkili kavramsal öğrenmelerinin sağlanmasıdır. Bu süreçte öğrenciler daha önce fark edilmemiş gerçek yaşam durumlarının içinde saklı kalmış önemli matematiksel kavramlara ve yapılara ulaşmaktadırlar. Örneğin Okulda Kermes modelleme etkinliğinde "en iyi yiyecek" bağlamıyla ilgili bir öğrencinin kendi hayat tecrübesinden getirdiği ve zihninde canlanan olguların bütünü, $o$ öğrencinin modeli olarak karşımıza çıkmaktadır. En iyi yiyeceğin matematiksel modeli ise toplam yiyecek maliyetinin hesaplanması ile başlayan ardından kârı hesaplayabilmek için dört işlemlere odaklanan denklemler ve işlemler gibi kavramsal yapıları içermektedir. Bu doğrultuda öğretim süreci ve örneği aynı zamanda model ve modelleme perspektifinin ortaya koyduğu model oluşturma etkinliklerine yön vermesi beklenen altı prensibi (Lesh, Hoover, Hole, Kelly ve Post, 2000) de içermektedir.

Model oluşturma etkinliklerinin prensipleri; (a) gerçeklik prensibi, (b) model oluşturma prensibi, (c) öz değerlendirme prensibi, (d) yapı belgelendirme prensibi, (e) model genelleme prensibi ve (f) etkili prototip prensibidir (Lesh, Hoover, Hole, Kelly ve Post, 2000). Okulda kermes model oluşturma etkinliği bu prensiplere göre incelenebilir. Gerçeklik prensibi, problem durumunun öğrencilerin gerçek yaşamında karşılaşabilecek ve anlamlandırabilecekleri bir durum olmasıdır. Okulda kermes problemini sunulduğu bağlamın gerçek yaşamlarında yer alan yiyecek seçimine yönelik olması gerçeklik prensibi ile ilgilidir. Problemin bağlamında bir yardım için hangi yiyeceğin seçilmesi gerektiğinin belirlenebilmesi için kâr modeli bir başka deyişle matematiksel bir yapı istenmesi, model oluşturma prensibi ile ilgilidir. Model oluşturma prensibi, öğrenciye sunulan problem durumu için bir çözüm olabilecek model (yapı) oluşturmaya, düzenlemeye ya da geliştirmeye ihtiyaç olduğunu hissettirebilmeli ve süreç sonunda öğrenci bir model oluşturabilmelidir. Okulda kermes probleminin, en iyi yiyeceği bulmak için öğrencilerin "en iyi" kelimesini farklı biçimlerde değerlendirme ve karar vermelerine olanak sağlaması, yiyeceği kârlı hale getirmenin yollarını öğrencilerin birlikte bulmalarına firsat tanıması ve kâr modeline ulaşmak için öğrencilerin farklı durumları (örneğin, 100 kişiye yiyecek alırsanız ancak sadece 64 kişi gelirse ne olur?) fark etmeleri öz değerlendirme prensibi ile ilgilidir. Çünkü öz değerlendirme prensibi, öğrencilerin çözümlerinin uygunluğunu ve kullanışlılığını, öğretmen onayı ya da desteği olmaksızın, kendi kendilerine değerlendirmeleri gerektiğini vurgulamaktadır. Problem bağlamında öğrencilerin buldukları kâr modelini bulma süreçlerinin yazılı bir metin hâlinde sunmalarının istenmesi yapı belgelendirme prensibi ile ilgilidir. Yapı belgelendirme prensibi, öğrencilerin etkinlik boyunca problem durumuyla ilgili çözüm yollarını ve düşüncelerini açıkça ortaya koyacak yazılı bir doküman oluşturmalarını gerektirmektedir. Okulda kermes problemi bağlamında oluşturulan kâr modeli, başka problem durumlarının kâr, zarar veya maliyet hesaplamalarında kullanılabileceği fikri model genelleme prensibi ile ilgilidir. Model genelleme prensibine göre öğrencilerin sadece özel ve belirli bir amaç veya durum için değil aynı zamanda farklı durumlar ve amaçlar için kullanılabilir model/ler geliştirmeleri gerekmektedir. Benzer başka problem durumları üzerinde çalışırken "Okulda Kermes" etkinliği hatırlatıldığında, öğrencilerin kullandıkları matematiksel ana fikri ve yöntemi bağlamıyla birlikte kolayca hatırlayabilecek olmaları etkili prototip (ilk örnek) prensibi ile ilgilidir. Bir başka deyişle bir model oluşturma etkinliği, bağlamı ve içerdiği matematiksel fikirleri ile öğrencinin aklında kalıcı olabildiği oranda etkili bir ilk örnektir. Böylece söz konusu prensip, "Geliştirilen model, yapısal olarak benzer diğer durumlar için kullanışlı bir ilk örnek (prototip) oluşturur mu?" sorusuna yanıt vermiş olur (Bukova Güzel ve diğerleri, 2018, s. 53).

\section{ÖNERILER}

Bu çalışma ile "İlkokulda matematiksel modelleme nasıl inşa edilmeli ve uygulanmalı?" sorusu yanıtlanmaya çalışılmıştır. Bundan sonraki çalışmalarda, Okulda Kermes gibi model 
oluşturma etkinliklerinin ilkokul öğrencilerine uygulanarak, onların modelleme süreçleri ve modelleme yeterlikleri değerlendirilebilir. Sınıf öğretmenlerine çalışma kapsamında ortaya konulan öğretim sürecine yönelik farkındalık kazandırılması için çalıştaylar düzenlenebilir. Benzer şekilde sınıf öğretmeni adaylarına lisans dönemindeki matematik öğretimi derslerinde, öğretim sürecine yönelik bilgi sahibi olmaları için ders içerikleri hazırlanabilir. Sınıf öğretmeni ve sınıf öğretmeni adaylarına Okulda Kermes model oluşturma etkinliğini uygulama noktasına taşımaları sağlanarak, uygulama süreçleri değerlendirilebilir. Ayrıca model oluşturma etkinlikleri sınıf öğretmeni ve sınıf öğretmeni adaylarına uygulanarak, onların modelleme süreçleri ve modelleme yeterlikleri değerlendirilebilir.

\section{KAYNAKÇA}

Akyol, D. ve Şendurur, P. (2016). Model oluşturma etkinliklerinde bilişsel araç kullanımının öğrenci düşünme becerilerine etkisi. Türk Bilgisayar ve Matematik Eğitimi Dergisi, 10(1), 101-129.

An, I. ve Oh, Y. (2018). An analysis of mathematical modeling process and mathematical reasoning ability by group organization method. Journal of Elementary Mathematics Education in Korea, 22(4), 497-516.

Bliss, K. ve Libertini, J. (2016). What is mathematical modeling? In S. Garfunkel and M. Montgomery (Ed.), GAIMME: Guidelines for assessment \& instruction in mathematical modeling education(pp. 7-21). Philadelphia, PA 19104 USA: Society for Industrial and Applied Mathematics SIAM. http://www.siam.org/reports/gaimmefull_color_for_online_viewing.pdf adresinden erişildi.

Blomhøj, M. ve Kjeldsen, T.H. (2006). Teaching mathematical modelling through project work. $Z D M, 38(2), 163-177$.

Blum, W. ve Niss, M. (1991). Applied mathematical problem solving, modelling, applications, and links to other subjects-State, trends and issues in mathematics instruction. Educational Studies in Mathematics, 22(1), 37-68.

Bukova Güzel, E., Tekin Dede, A., Hıdıroğlu, Ç.N., Kula Ünver, S. ve Özaltun Çelik, A. (2018).Matematiksel modellemeye giriş. In E. Bukova Güzel (Eds.), Matematik eğitiminde matematiksel modelleme (pp.1-16).Ankara: Anı Yayıncılık.

Bukova Güzel, E., Tekin Dede, A., Hıdıroğlu, Ç.N., Kula Ünver, S. ve Özaltun Çelik, A. (2018).Modelleme etkinliklerinin öğretimde kullanımı. In E. Bukova Güzel (Eds.), Matematik eğitiminde matematiksel modelleme (pp. 45-82).Ankara: Anı Yayınc1lık.

Carlson, M.A., Wickstrom, M.H., Burroughs, E.A. ve Fulton, E.W. (2016). A case for mathematical modeling in the elementary school classroom. In C. R. Hirsch and A. R. McDuffie (Eds.), Mathematical modeling and modeling mathematics (pp. 121-129). Reston, VA: National Council of Teachers of Mathematics.

Çavuş Erdem, Z. ve Gürbüz, R. (2018). Matematik modelleme etkinliklerine dayalı öğrenme ortamında yedinci sınıf öğrencilerinin alan ölçme bilgi ve becerilerinin incelenmesi. Adlyaman Üniversitesi Ĕ̈itim Bilimleri Dergisi, 8(2), 86-115.

Darling-Hammond, L. ve Austin, K. (2014). Lessons for life: Learning and transfer. http://www.learner.org adresinden erişildi.

De Corte, E. (2004). Mainstreams and perspectives in research on learning mathematics from instruction. Applied Psychology, 53, 279-310. 
Deniz, D. ve Akgün, L. (2016). Ortaöğretim matematik öğretmenlerinin model oluşturma etkinliği tasarım prensiplerine uygun etkinlik tasarlayabilme yeterlikleri. Karaelmas Eğitim Bilimleri Dergisi, 4, 1-14.

Doğan, M. F., Gürbüz, R., Çavuş Erdem, Z. ve Şahin, S. (2018). STEM eğitimine geçişte bir araç olarak matematiksel modelleme. In R. Gürbüz and M. F. Doğan (Eds.), Matematiksel modellemeye disiplinler arası bakış: Bir STEM yaklaşımı (pp. 43-56). Ankara: Pegem Akademi.

English, L.D. (2003a). Mathematical modelling with young learners. In S. J. Lamon, W. A. Parker and S. K. Houston (Eds.), Mathematical modelling: A way of life(pp. 3- 18). Chichester, UK: Horwood.

English, L.D. (2006). Mathematical modeling in the elementary school: Children's construction of a consumer guide. Educational Studies in Mathematics, 63(3), 303-323.

English, L.D. (2007). Interdisciplinary modelling in the elementary mathematics curriculum. In J. Watson and K. Beswick (Eds.), Mathematics: Essential Research, Essential Practice içinde (pp.275-284). Australia: MERGA Inc.

English, L.D. (2010). Young children's early modelling with data. Mathematics Education Research Journal, 22(2), 24-47.

English, L.D. (2012). Data modelling with first-grade students. Educational Studies in Mathematics, 81(1), 15-30.

English, L.D., Fox, J. L. ve Watters, J. J. (2005). Problem posing and solving with mathematical modeling. Teaching Children Mathematics, 12(3), 156.

English, L.D. ve Watters, J.J. (2004). Mathematical modelling with young children. International Group for the Psychology of Mathematics Education, 2, 335-342.

English, L.D. ve Watters, J.J. (2005). Mathematical modeling in third-grade classrooms. Mathematics Education Research Journal, 16, 59-80.

Greer, B. (1997). Modelling reality in mathematics classrooms: The case of word problems. Learning and Instruction, 7(4), 293-307.

Hıdıroğlu, Ç.N. ve Bukova Güzel, E. (2016). Teknoloji destekli ortamda matematiksel modelleme sürecindeki bilişsel ve üst bilişsel eylemler arasındaki geçişler. Necatibey Eğitim Fakültesi Elektronik Fen ve Matematik Eğitimi Dergisi, 10(1), 313-350.

Hıdıroğlu, Ç.N. ve Özkan Hıdıroğlu, Y. (2017). Altıncı sınıf öğrencilerinin matematiksel modellemede oluşturdukları gerçek yaşam problem durumu modelleri. Ilköğretim Online, 16(4), 1702-1731.

Iş1k, A. ve Mercan, E. (2015). Ortaokul matematik öğretmenlerinin model ve modelleme hakkındaki görüşlerinin incelenmesi. Kastamonu Eğitim Dergisi, 23(4), 1835-1850.

İnan Tutkun, M. ve Didiş Kabar, M.G. (2018). Ortaokullarda matematiksel modelleme: 7. sınıf öğrencilerinin "hava durumu" modelleme problemi ile deneyimi. Adlyaman Üniversitesi Ĕ̈itim Bilimleri Dergisi, 8, 23-52.

Ko, C. ve Oh, Y. (2015). The effects of mathematical modeling activities on mathematical problem solving and mathematical dispositions. Journal of Elementary Mathematics Education in Korea, 19(3), 347-370.

Lesh, R. A., Hamilton, E. ve Kaput, J. J. (2007). Foundations for the future in mathematics education. Mahwah, NJ: Lawrance Erlbaum.

Lesh, R., Hoover, M., Hole, B., Kelly, A. ve Post, T. (2000). Principles for developing thoughtrevealing activities for students and teachers. In A. Kelly and R. Lesh (Eds.), Handbook 
of research in mathematics and science education (pp. 113-149). Mahwah, NJ: Lawrence Erlbaumand Associates.

Lesh, R. ve Doerr, H. (2003). Foundations of a models and modeling perspective on mathematics teaching, learning, and problem solving. In R. Lesh and H. M. Doerr (Eds.), Beyond constructivism: Models and modeling perspective on mathematics problem solving, learning, and teaching (pp. 3-34). Mahwah, NJ: Lawrence Erlbaum Associates, Inc.

Lesh, R. ve Fennewald, T. (2010). Introduction to part I modeling: What is it? Why do it? In R. Lesh, P. L. Galbraith, C. R. Haines and A. Hurford (Eds.), Modeling students' mathematical modeling competencies: ICTMA 13 (pp. 5-10). New York, NY: Springer.

Lingefjärd, T. (2006). Faces of mathematical modeling. ZDM, 38(2), 96-112.

Maaß, K. (2006). What are modelling competencies? ZDM, 38(2), 113-142.

Milli Eğitim Bakanlığı [MEB]. (2015). Illkokul matematik dersi (1-4) ögretim programı. Ankara: Talim ve Terbiye Kurulu Başkanlığı.

Milli Eğitim Bakanlığı [MEB]. (2018). Illkokul matematik (1-4. Sinıflar) dersi öğretim programı. Ankara: Talim Terbiye Başkanlığı Yayınları.

Mousoulides, M., Pittalis, M. ve Christou, C. (2006). Improving mathematical knowledge through modeling in elementary schools. In J. Novotna, H. Moraova, M. Kratka and N. Stehlikova (Eds.), Proceedings 30th Conference of the International Group for the Psychology of Mathematics Education(pp.201- 208). Prague, Czech Republic: Charles University in Prague Faculty of Education.

Mousoulides, N.G., Christou, C. ve Sriraman, B. (2008). A modeling perspective on the teaching and learning of mathematical problem solving. Mathematical Thinking and Learning, 10(3), 293-304.

National Council of Teachers of Mathematics [NCTM] (2000). Principles and standarts for school mathematics. Virginia: NCTM Publications.

Organisation for Economic Co-operation and Development [OECD]. (2019a). PISA 2018 assessment and analyticalframework. Paris: OECD Publishing.

Organisation for Economic Co-operation and Development [OECD]. (2019b). PISA 2018 results volume I: What students know and can do. Paris: OECD Publishing.

Özaltun Çelik, Ö. ve Bukova Güzel, E. (2018). Doğrusal fonksiyonun öğrenilmesine yönelik tasarlanan matematiksel modelleme etkinliği üzerine çalışan öğrencilerin nicel muhakemeleri. Adiyaman Üniversitesi Eğitim Bilimleri Dergisi, Özel Sayı, 53-85.

Özer, A.Ö. ve Bukova Güzel, E. (2016). Öğrenci, öğretmen adayı ve öğretmenlerin bakış açısından matematiksel modelleme problemleri. Manisa Celal Bayar Üniversitesi Eğitim Fakültesi Dergisi, 4(1), 57-73.

Panaoura, A. (2012). Improving problem solving ability in mathematics by using a mathematical model: A computerized approach. Computers in Human Behavior, 28(6), 2291-2297.

Skolverket (1997). Kommentar till grundskolans kursplan och betygskriterier $i$ matematik [Commentary on the comprehensive school curriculum and marking criteria in mathematics]. Stockholm: Liber Utbildningsförlaget.

Sönmez, M.T. (2019). Yedinci sınıf öğrencilerin matematiksel modelleme sürecinde orantısal ak1l yürütmelerini etkileyen faktörler. Ilkogretim Online, 18(2), 734-759.

Steen, L.A., Turner, R. ve Burkhardt, H. (2007). Developing mathematical literacy. In W. Blum., P. L. Galbraith, H. W. Henn and M. Niiss (Eds.), Modelling and applications in mathematics education (pp. 285-294). New York: Springer. 
Stillman, G., Galbraith, P., Brown, J. ve Edwards, I. (2007). A framework for success in implementing mathematical modelling in the secondary classroom. Mathematics: Essential Research, Essential Practice, 2, 688-697.

Suh, J.M., Matson, K. ve Seshaiyer, P. (2017). Engaging elementary students in the creative process of mathematizing their world through mathematical modeling. Education Sciences, 7(2), 62.

Swedish Ministry of Education. (1994). Kursplaner för grundskolan. [Syllabus for subjects in the comprehensive school curriculum]. Stockholm, Fritzes.

Şahin, N. (2014). İlkokul 4. sını öğrencilerinin model oluşturma etkinlikleri üzerindeki düşünme süreçleri. Yayımlanmamış yüksek lisans tezi. Ondokuz Mayıs Üniversitesi, Samsun.

Şahin, N. (2019). Illkokul 4. sını ögrencilerinin bilişsel modelleme yeterliklerinin belirlenmesi ve değerlendirilmesi. Yayımlanmamış doktora tezi. Ondokuz Mayıs Üniversitesi, Samsun.

Şahin, N. ve Eraslan, A. (2016). İlkokul öğrencilerinin modelleme süreçleri: suç problemi. Eğitim ve Bilim, 41(183), 47-67.

Şahin, N. ve Eraslan, A. (2017). Fourth-grade elementary school students' thought processes and challenges encountered during the butter beans problem. Educational Sciences: Theory \& Practice, 17(1), 105-127.

Şahin, N. ve Eraslan, A. (2018). İlkokulda model oluşturma etkinlikleri nasıl uygulanmalı? Eğitim Kuram ve Uygulama Araştırmaları Dergisi, 4(1), 99-117.

Şahin, S., Doğan, M.F., Gürbüz, R. ve Çavuş-Erdem, Z. (2017). Öğretmen adaylarının matematiksel modelleme problemi hazırlama becerileri. Paper presented at the International Symposium of Turkish Computer and Mathematics Education-3 (pp. 582584), Afyon.

Tekin Dede, A. ve Yılmaz, S. (2013). İlköğretim matematik öğretmeni adaylarının modelleme yeterliliklerinin incelenmesi. Türk Bilgisayar ve Matematik Eğitimi Dergisi, 4(3), 185206.

Tran, D. ve Dougherty, B.J. (2014). Authenticity of mathematical modeling. Mathematics Teacher, 107(9), 672-678.

Ulu, M. (2017). Examining the mathematical modeling processes of elementary school 4thgrade students: Shopping problem. Universal Journal of Educational Research, 5(4), 561-580.

Verschaffel, L., De Corte, E. ve Vierstraete, H. (1999). Upper elementary school pupils' difficulties in modeling and solving nonstandard additive word problems involving ordinal numbers. Journal for Research in Mathematics Education, 30(3), 265.

Verschaffel, L. ve De Corte, E. (1997). Teaching realistic mathematical modeling in the elementary school: A teaching experiment with fifth graders. Journal for Research in mathematics education, 577-601.

Watters, J.J., English, L.D. ve Mahoney, S. (2004). Mathematical modeling in the elementary school. American Educational Research Association Annual Meeting toplantisinda sunulmuş sözlü bildiri. ABD: San Diego.

Wickstrom, M.H. (2017). Mathematical modeling: Challenging the figured worlds of elementary mathematics. In E. Galindo and J. Newton (Eds.), Proceedings of the 39th annual meeting of the North American Chapter of the International Group for the 
Psychology of Mathematics Education(pp. 685-692). Indianapolis, IN: Hoosier Association of Mathematics Teacher Educators.

Xin, Z., Lin, C., Zhang, L. ve Yan, R. (2007). The performance of Chinese elementary school students on realistic arithmetic word problems. Educational Psychology in Practice, 23(2), 145-159.

Zawojevski, S.J., Lesh, R. ve English, L. (2003). A models and modeling perspective on the role of small group learning activities. In R. Lesh and H. M. Doerr (Eds.), Beyond constructivism: A models and modeling perspective on mathematics problem solving, learning ve teaching(pp. 337- 358). Mahwah, NJ: Lawrence Erlbaum Associates.

\section{EXTENDED ABSTRACT}

It aims to raise individuals who can make sense of what they have learned and create their own meanings around the primary school mathematics curriculum and in the school environment, and apply their meanings to the situations they encounter in daily life. In this context, mathematics education has been directed to the applications where meaningful relationships are established between mathematics and daily life (De Corte, 2004). With the importance of mathematics and daily life in mathematics teaching, mathematical model and modeling processes appear in teaching and teaching processes (Lesh, Hamilton, \& Kaput, 2007).

Mathematical modeling is a process in which mathematics is used to represent real world phenomena, to analyze, to make predictions or to provide insight in another way (Bliss, \& Libertini, 2016). According to Lesh, \& Doerr (2003), mathematical modeling is expressed as a step in model building activities or as a process that takes place during the model building activities. In this direction, modeling activities are non-routine, real-life-related problem types that contain different probable solutions, which are desired to produce many probabilistic solutions in order to create a model that can be generalized and prototyped by working together in groups (Lesh and Doerr, 2003). In the national literature, limited study has been reached to examine the model building processes of primary school students (Şahin, 2014, 2019; Şahin, \& Eraslan, 2016, 2017, 2018; Ulu, 2017). When the limited number of studies conducted for the primary school period is examined, it is revealed that the focus of the research is modeling processes. However, there are no studies on what kind of applications should be done for the use of mathematical modeling in the primary school and its sample applications. In the study conducted by Şahin, \& Eraslan (2018), "How should modeling activities be implemented in primary school?" The answer to the question was sought. However, in this study, modeling activities are included in a general framework that will cover every level of education. Therefore, "How should mathematical modeling be built and applied in primary school period?" The question appears to be necessary to answer. Considering this deficiency, it is considered important to expand mathematical modeling activities in primary school period and to provide primary school teachers with a teaching framework and exemplary activities that they can use in the learning-teaching process. In this context, the aim of the research is to present a teaching framework put forward by Carlson, Wickstrom, Burroughs, \& Fulton (2016) in order to apply mathematical modeling in primary school period and to include an example of modeling activity in this framework.

Carlson, Wickstrom, Burroughs, \& Fulton (2016) have introduced a teaching framework for mathematical modeling in primary school classes. This teaching framework consists of "developing", "enacting" and "revisiting" steps.

The Fundraising Dinner problem was adapted to Turkish from the work of Carlson, Wickstrom, Burroughs, \& Fulton (2016). In the adaptation process, attention was paid to ensure that the problem is appropriate and understandable to the age level of primary school students. The Fundraising Dinner problem is a dinner and a modeling activity for fundraising to be made 
at school. "What is the best meal for a dinner and fundraising?" With the problem students start to participate in the modeling process.

In the Fundraising Dinner problem, students are asked to collect data, determine the variables and limitations, interpret, analyze and combine them, associate the qualitative data with the quantitative data and create a profit model. In addition, this problem, as suggested by Doerr, \& English (2003), is a model building activity that allows students to do group work, present the data in a problem state in various representation formats, create a generalized and prototype model, and share the solutions they reach in written and verbally.

In this study, a teaching framework that was put forward by Carlson, Wickstrom, Burroughs and Fulton (2016) was presented to apply mathematical modeling in the primary school period, and an example of a modeling activity for primary school students was given in this frame. When this teaching framework is examined, it is believed that the model and modeling perspective, which takes mathematical modeling with a context-based approach in recent years, is based on the theoretical approach. According to this theoretical approach, modeling activities enable students to interpret a real life situation and to mathize it in a way that they can make sense (Lesh, \& Doerr, 2003). The main purpose of this approach is to provide students with more effective conceptual learning by making use of the relationship between mathematical concepts and processes with real life. In this process, students reach important mathematical concepts and structures hidden in real life situations that were not noticed before. For example, in the Fundraising Dinnermodeling activity, all of the cases brought to life in the mind of a student brought from a student's own life experience related to the "best meal" context appear as the model of that student. The mathematical model of the best food includes conceptual structures such as equations and operations that begin with the calculation of the total food cost and then focus on four operations to calculate profit. Accordingly, the teaching framework and example also includes six principles (Lesh, Hoover, Hole, Kelly, \& Post, 2000), which are expected to guide modeling activities set out by the model and modeling perspective. 